\title{
Analisis Kekuatan Struktur Wereable Elbow Exoskeleton untuk Penderita Kelumpuhan Gerak Siku Menggunakan Finite Element Method (FEM)
}

\author{
* Rifky Ismail ${ }^{1,2}$ Frandy A Sitanggang ${ }^{1}$ dan Mochammad Ariyanto ${ }^{1,2}$ \\ ${ }^{1}$ Departemen Teknik Mesin, Fakultas Teknik, Universitas Diponegoro \\ Jl. Prof. Sudharto Kampus UNDIP Tembalang Semarang 50275 \\ ${ }^{1}$ Center for Biomechanics, Biomaterials, Biomechatronics and BioSignal Processing (CBIOM3S) \\ Pusat Unggulan Iptek Perguruan Tinggi (PUI PT) UNDIP \\ J1. Prof. Sudharto Kampus UNDIP Tembalang Semarang 50275 \\ *E-mail: ismail.rifky@gmail.com
}

\begin{abstract}
The development of wearable elbow exoskeletons is in line with the development of robotics, where for some purposes to be used requires adjustments to material use. In the development of robotics, the types of robots are divided into 2 types, namely hard robotic and soft robotic based on the material used. On robotic wearable exoskeletons also adapting material developments that can support ergonomic values for patients to use it more comfortably. In Indonesia, research on elbow exoskeletons has been carried out (Ismail, 2018), but it is necessary to test the structural strength of these therapeutic devices. In this study we will discuss the strength of the structure of the Wearable Elbow Exoskeleton that has been designed using the Finite Element Method where objects consist of an infinite number of elements that compose them. In the absence of the finite element method it will be very difficult to analyze the stress or deformation. To facilitate the analysis it can be assumed that an object consists of a finite number of elements. The finite element method is a method that approaches by assuming an object consists of finite elements. These elements are considered separate and are connected to a point called a nodal point so that it forms a net, the smaller the size of the element, the smaller the error that arises. The simulation process is given some limitations that are used in the simulation. In boundary condition, we determine the loads that work on the geometry and what supports are used in geometry. The boundary condition specified in the simulation must be as much as possible with the actual conditions, because it will affect the results that will be obtained in the simulation process. From the simulation results obtained in the motor-linkage section the maximum voltage is $0.0016 \mathrm{MPa}$ and safety factor of 13.05, the maximum linkage received is $58.461 \mathrm{MPa}$ and the safety factor is 3.561, while the base maximum voltage received is $7.624 \mathrm{MPa}$ and the safety factor amounting to 3,542. From these results it can be concluded if the parts that are considered prone to failure are considered to have sufficient safety factors to be used even at the maximum stress
\end{abstract}

Keywords: Finite element method; von mises; brachialis plexus injury

\section{ABSTRAK}

Perkembangan wearable elbow exoskeleton sejalan dengan perkembangan robotika, dimana untuk beberapa keperluan untuk digunakan membutuhkan penyesuaian pada penggunaan material. Pada perkembangan robotika, jenis robot dibedakan menjadi 2 jenis yaitu hard robotic dan soft robotic berdasarkan material yang digunakan.. Pada wearable exoskeleton robotic juga mengadaptasi perkembangan material yang dapat menunjang nilai ergonomi untuk penderita dapat menggunakannya lebih nyaman lagi. Di Indonesia riset tentang elbow exoskeleton sudah dilakukan (Ismail, 2018), namun perlu ada nya pengujian kekuatan struktur dari alat terapi tersebut. Dalam penelitian ini akan membahas kekuatan struktur dari wearable elbow exoskeleton yang sudah dirancang dengan menggunakan Metode Elemen Hingga dimana benda terdiri dari tak terhingga elemen yang menyusunnya. Dengan tidak adanya metode elemen hingga tersebut maka akan sangat sulit untuk dianalisis tegangan atau deformasinya. Untuk memudahkan analisis tersebut dapat dianggap bahwa suatu benda terdiri dari jumlah berhingga elemen. Metode elemen hingga adalah sebuah metode yang melakukan pendekatan dengan menganggap suatu benda terdiri dari berhingga elemen. Elemenelemen tersebut dianggap terpisah dan dihubungkan dengan titik yang dinamakan titik nodal sehingga membentuk suatu jaring, Semakin kecil ukuran elemen, semakin kecil kesalahan yang timbul. Proses simulasi ini diberikan beberapa batasan-batasan yang digunakan pada simulasi. Pada boundary condition, ditentukan beban-beban yang bekerja pada geometri dan tumpuan apa saja yang digunakan pada geometri. Boundary condition yang ditetapkan pada simulasi harus sebisa mungkin sama dengan kondisi yang sebenarnya, karena akan mempengaruhi hasil yang akan didapatkan pada proses simulasi. Dari hasil simulasi didapatkan pada bagian motor-linkage tegangan maksimum sebesar $0.0016 \mathrm{MPa}$ 
dan safety factor sebesar 13,05, pada Linkage tegangan maksimum yang diterima sebesar 58,461 MPa dan safety factor sebesar 3,561, sedangkan pada base tegangan maksimum yang diterima sebesar 7,624 MPa dan safety factor sebesar 3,542. Dari hasil tersebut dapat disimpulkan jika pada bagian-bagian yang dianggap rawan untuk terjadi kegagalan dinilai memiliki faktor keamanan yang cukup baik untuk digunakan bahkan pada tegangan maksimumnya.

Kata kunci: Metode elemen hingga; von mises; brachial plexus injury

\section{Pendahuluan}

Pengembangan wearable exoskeleton robotic mempunyai tujuan yang berbeda-beda, diantaranya dapat diterapkan pada orang dengan penyakit stroke, sebagai alat bantu gerak penderita disabilitas fungsi tangan, dan alat bantu di bidang industri maupun rehabilitasi pada rumah sakit. Perkembangan wearable exoskeleton sejalan dengan perkembangan robotika, dimana untuk beberapa keperluan untuk digunakan membutuhkan penyesuaian pada penggunaan material. Pada perkembangan robotika, jenis robot dibedakan menjadi 2 jenis yaitu hard robotic dan soft robotic berdasarkan material yang digunakan. Hard robotic merupakan sebuah mesin yang dirancang untuk melakukan pekerjaan secara spesifik, dan berulang ulang. Sedangkan soft robotic merupakan sub-bidang dari robotik yang dirancang menggunakan material yang "compliant" (dapat menyesuaikan sesuai dengan kebutuhan), mirip dengan yang ditemukan pada organisme hidup dengan menggunakan material yang lebih nyaman untuk diaplikasikan pada manusia. Pada wearable exoskeleton robotic juga mengadaptasi perkembangan material yang dapat menunjang nilai ergonomi untuk penderita dapat menggunakannya lebih nyaman lagi.

Karena pengembangan exoskeleton yang bisa dikembangkan sangat luas, oleh sebab itu exoskeleton diklasifikasikan menjadi 5 bidang dasar pengembangan yaitu segmen pengaplikasian pada tubuh, derajat kebebasan / degree of fredom (DOF) yang dapat dicapai alat, tipe penggerak, metode transmisi daya, pengaplikasian alat, serta klasifikasi tambahan seperti model linkage configuration dan metode kontrol. Dalam pengembangan desain exoskeleton itu sendiri akan sangat tergantung dari beberapa klasifikasi yang disebutkan diatas [1].

Penelitian di dunia telah sangat maju berkaitan dengan exoskeleton [2-8]. Beberapa diantaranya berkaitan dengan upaya membantu pasien untuk dapat memulihkan kembali gerakan tangan melalui proses terapi sehingga proses pemulihannya bisa lebih cepat. Alat bantu gerak yang digunakan ini berupa wearable exoskeleton dengan spesifikasi untuk membantu gerakan jari tangan, pergelangan dan siku pasien yang mengalami kelumpuhan gerak anggita bagian tubuh atas. Beberapa penelitian di berbagai penjuru dunia berkaitan dengan upaya membangun suatu peralatan yang dapat digunakan oleh pasien untuk sehari-hari telah mencapai kemajuan yang cukup pesat. Dalam kasus wearable exoskeleton, penggunaan alat yang digunakan untuk kehidupan sehari-hari akan membutuhkan perancangan dan pengujian yang mendalam sehingga pasien dapat nyaman menggunakan, kuat menahan beban dan dapat digunakan untuk waktu yang lama.

Saat ini di Center for Biomechanics, Biomaterials, Biomechatronics and BioSignal Processing (CBIOM3S) Pusat Unggulan Iptek Perguruan Tinggi (PUI PT) Universitas Diponegoro telah dilakukan penelitian tentang tentang wearable elbow exoskeleton yanga khusus dipakai untuk membantu gerak pasien yang mengalami kelumpuhan gerak siku. Penelitian ini merupakan kelanjutan dari penelitan tentang tangan bionik yang telah banyak dipublikasikan sebelumnya [9-11]. Produk wearable elbow exoskeleton sedang dalam proses pengurusan paten sehingga tidak dapat banyak dimasukkan dalam paper ini. Dalam salah satu prosesnya, produk wearable elbow exoskeleton ini perlu ada nya pengujian kekuatan struktur dan analisis pembebanan. Dimensi dari 3 part utama yang menanggung beban: part base, linkage dan penyambung gear - linkage pada wearable elbow exoskeleton produk ini telah ditetapkan. Kajian metode elemen hingga dibutuhkan untuk mengetahui apakah dimensi yang telah dipilih ini mampu menahan beban tangan pasien yang akan digerakkan. Tujuan dalam penelitian ini adalah kajian kekuatan struktur dari wearable elbow exoskeleton produk CBIOM3S UNDIP yang sudah dirancang dengan menggunakan alat bantu perhitungan Metode Elemen Hingga/Finite Element Method (FEM) dengan menekankan pada pembahasan analisis tegangan dan safety factor dari ketiga part utama yang menahan beban lengan pasien.

\section{Material dan Metode Penelitian}

Dalam penelitian ini ada 3 part yang akan di analisis yaitu part base, linkage dan penyambung gear - linkage. Wearable elbow exoskeleton dibuat menggunakan bahan-bahan polimer seperti poly lactic acid (PLA), aluminium dan PVC. Berikut merupakan sifat mekanik material yang digunakan dalam pengujian penelitian ini. Proses simulasi ini diberikan beberapa batasan-batasan yang digunakan pada simulasi. Pada boundary condition, ditentukan beban-beban yang bekerja pada geometri dan tumpuan apa saja yang digunakan pada geometri. Boundary condition yang ditetapkan pada simulasi harus sebisa mungkin sama dengan kondisi yang sebenarnya, karena akan mempengaruhi hasil yang akan didapatkan pada proses simulasi. 

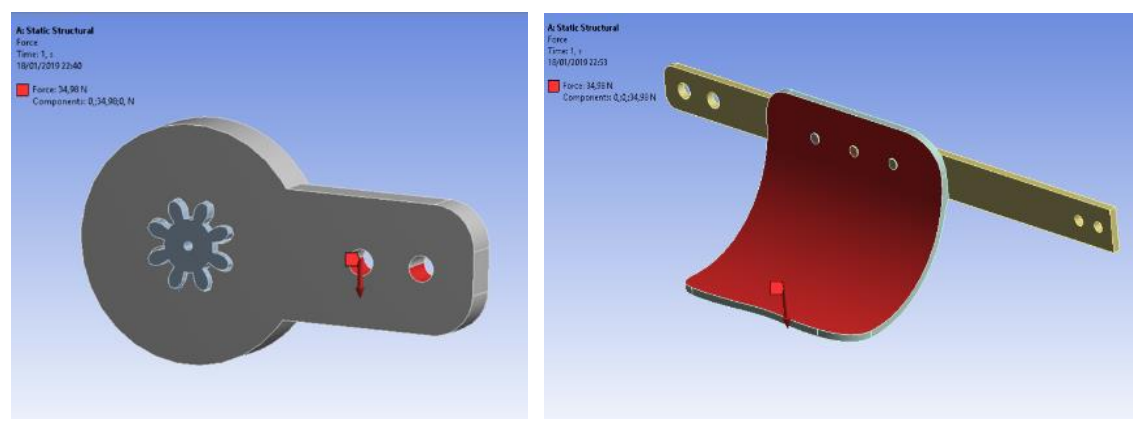

Gambar 1. (a) Part penyambung gear-linkage (b) Part base dan linkage

Tabel 1. Sifat mekanik PLA

\begin{tabular}{cc}
\hline Keterangan & Nilai \\
\hline Densitas & $1,23 \mathrm{gr} / \mathrm{cm}^{3}$ \\
Tensile Strength & $42,57 \mathrm{MPa}$ \\
Poisson's Ratio & 0,3 \\
Modulus Young & $2,3 \mathrm{GPa}$ \\
\hline
\end{tabular}

Tabel 2. Sifat mekanik aluminium

\begin{tabular}{cc}
\hline Keterangan & Nilai \\
\hline Densitas & $2,74 \mathrm{gr} / \mathrm{cm}^{3}$ \\
Tensile strength & $392 \mathrm{MPa}$ \\
Poisson's Ratio & 0,33 \\
Modulus Young & $73 \mathrm{GPa}$ \\
\hline
\end{tabular}

Tabel 3. Sifat mekanik PVC (Polyvinyl Chloride)

\begin{tabular}{cc}
\hline Keterangan & Nilai \\
\hline Densitas & $1,3 \mathrm{gr} / \mathrm{cm}^{3}$ \\
Tensile strength & $41,4 \mathrm{MPa}$ \\
Poisson's Ratio & 0,33 \\
Modulus Young & $2,480 \mathrm{GPa}$
\end{tabular}

\subsection{Gaya}

Gaya yang bekerja pada simulasi ini terletak pada sumbu vertical terhadap Y dimana gaya merupakan hasil dari berat tangan 1,54 kg dan ditambah beban maksimum yang dapat ditahan oleh alat dengan torsi 9,2 N.m yaitu $2 \mathrm{~kg}$. lalu dikalikan dengan gaya gravitasi bumi maka F yang didapat yaitu 34,98 N. Gambar 2 merupakan gaya yang bekerja pada model simulasi

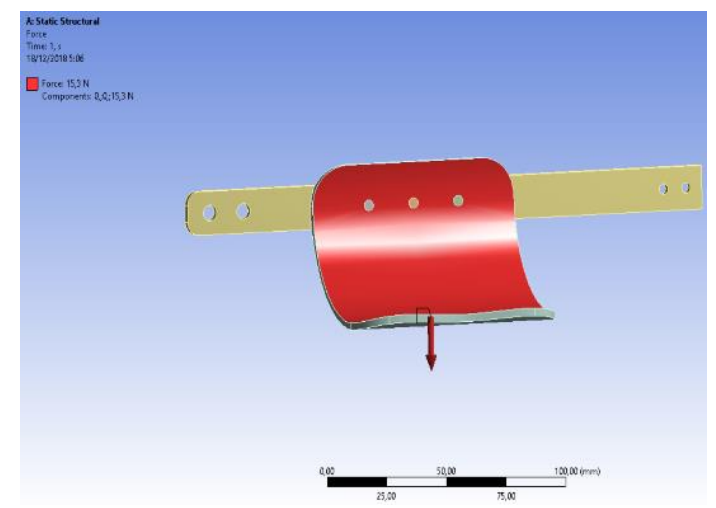

Gambar 2. Gaya yang bekerja pada model simulasi. 


\subsection{Jenis Support}

Support yang diberikan pada simulasi ini adalah fix support, karena pada perhitungan beban menggunakan persamaan kesetimbangan moment gaya. Maka benda akan dianggap tetap dan tidak mengalami perpindahan sama sekali. Gambar 3 adalah tumpuan fix support pada bagian permukaan model.

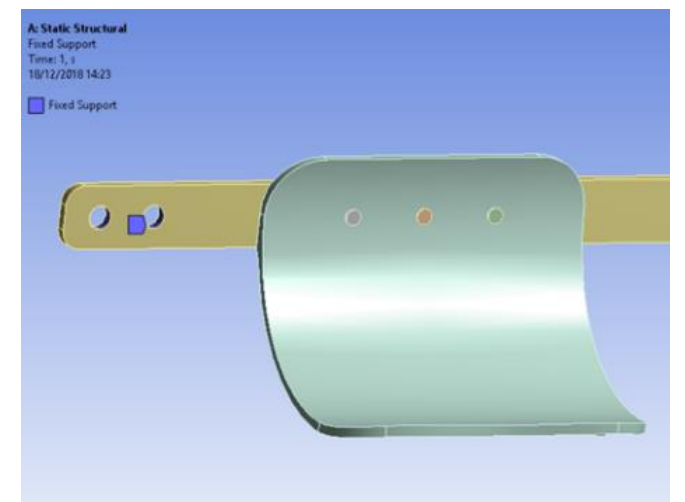

Gambar 3. Tumpuan fix support pada bagian permukaan model

\subsection{Mesh Study}

Untuk mesh study disini menggunakan fiture converegen dari software, dengan fungsi ini software akan mencari sendiri dimana nilai optimum dari mesh yang akan digunakan, dimana dengan adanya perubahan mesh tidak terjadi perubahan tegangan. Gambar 4 adalah hasil mesh pada model.

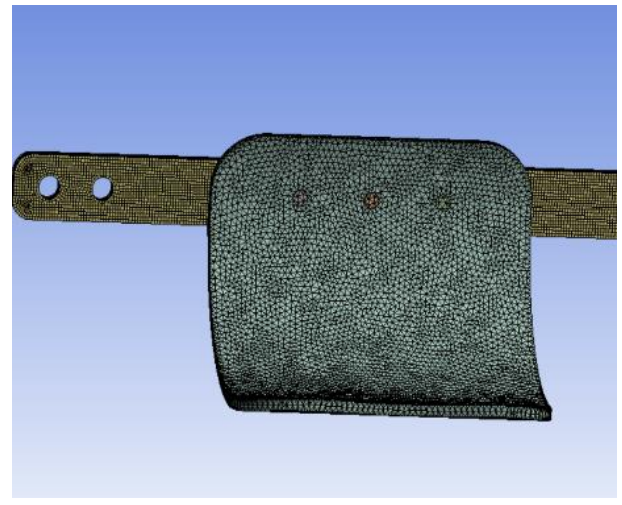

Gambar 4. Hasil mesh pada model
Tabel 4. Hasil variasi Mesh

\begin{tabular}{cc}
\hline Elemen Size (mm) & Tegangan(MPa) \\
\hline 4,25 & 15,635 \\
3,25 & 15,817 \\
2,25 & 18,195 \\
1,25 & 19,296 \\
1 & 19,451 \\
0,75 & 19,54 \\
\hline
\end{tabular}

Pada sample part tersebut, di ujikan ukuran kekasaran mesh sebesar 4,25 mm, 3,25 mm, 2,25 mm, 1,25 mm, 1 $\mathrm{mm}$, dan 0,75 mm. Dari pengujian variasi tersebut, didapatkan hasil seperti pada Tabel 4. Dari hasil pengujian variasi mesh tersebut, mesh ukuran 2,25 mm dan 1,25 mm menunjukkan perbedaan yang kecil, sehingga dapat disimpulkan bahwa pada ukuran ini, hasil dari pengujian cukup steady dan dapat digunakan untuk ukuran mesh pada simulasi selanjutnya.

\section{Hasil dan Pembahasan}

Hasil pengujian didapat dari simulasi analisis pembebanan statik dengan menggunakan software metode elemen hingga. Gaya yang bekerja pada simulasi ini terletak pada sumbu vertikal terhadap Y dimana gaya merupakan hasil dari berat tangan 1,54 kg dikalikan dengan gaya gravitasi bumi yaitu 15,3 N. Support yang diberikan pada simulasi ini adalah fix support, karena pada perhitungan beban menggunakan persamaan kesetimbangan moment gaya. Maka benda akan dianggap tetap dan tidak mengalami perpindahan sama sekali. Untuk mesh study disini menggunakan fiture converegen dari software metode elemen hingga, dengan fungsi ini software metode elemen hingga akan mencari sendiri dimana nilai optimum dari mesh yang akan digunakan, dimana dengan adanya perubahan mesh tidak terjadi perubahan tegangan. 
Selanjutnya data dari gaya yang dialami, mechanical properties dari material yang akan disimulasi, dan kondisi batas pada simulasi sudah ditetapkan maka langkah selanjutnya adalah melakukan running simulasi menggunakan software metode elemen hingga. Part yang akan disimulasikan merupakan part yang cenderung mengalami kegagalan dan part yang terkena beban atau gaya. Hasil dari simulasi tersebut dapat dilihat tegangan maksimum dan safety factor terjadi pada 3 part cukup tinggi dimana safety factor pada ketiga part lebih besar dari 1 maka dikatakan part tersebut aman namun dengan nilai safety factor tersebut termasuk dikategorikan terlalu besar maka perlunya dilakukan optimasi pada setiap part.

Untuk bagian motor-linkage tegangan maksimum sebesar $0.000433 \mathrm{MPa}$ dan safety factor sebesar 15 pada daerah yang ditunjukkan oleh Gambar 5 dan Gambar 6. Pada linkage tegangan maksimum yang diterima sebesar 25,41 MPa dan safety factor sebesar 7,94 pada daerah yang ditunjukkan oleh Gambar 5 dan Gambar 6. Sedangkan pada base tegangan maksimum yang diterima sebesar 3,287 MPa dan safety factor sebesar 8,26 pada daerah yang ditunjukkan oleh Gambar 5 dan Gambar 6. Dari hasil tersebut dapat disimpulkan jika pada bagian-bagian yang dianggap rawan untuk terjadi kegagalan dinilai memiliki faktor keamanan yang cukup baik untuk digunakan bahkan pada tegangan maksimumnya. Hasil dari simulasi dapat dilihat pada Tabel 5.

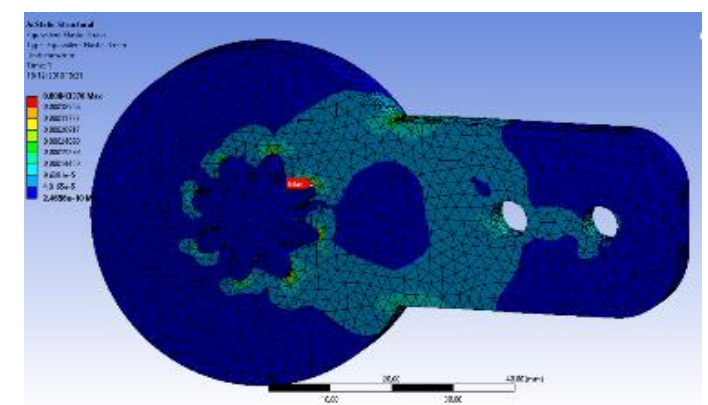

(a)

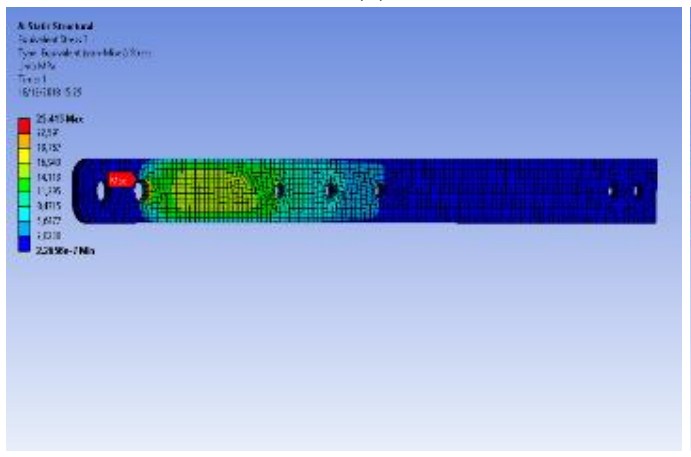

(c)

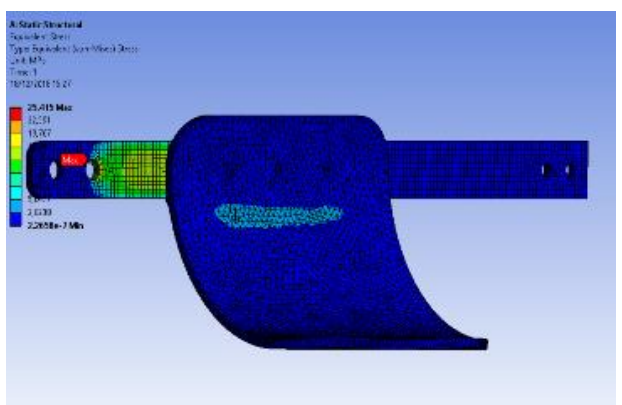

(b)

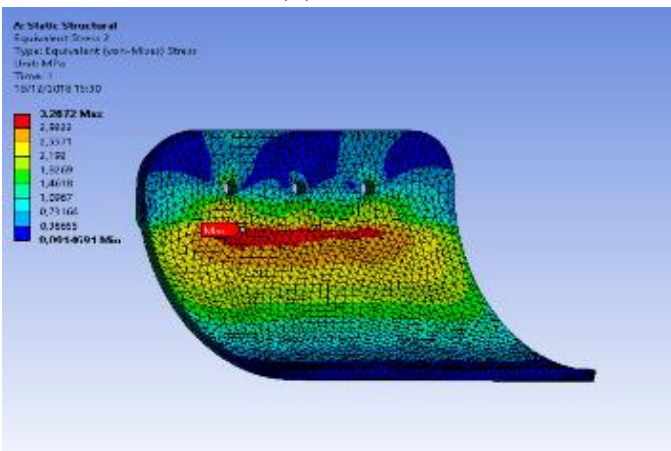

(d)

Gambar 5 Tegangan maksimum dari hasil simulasi pembebanan

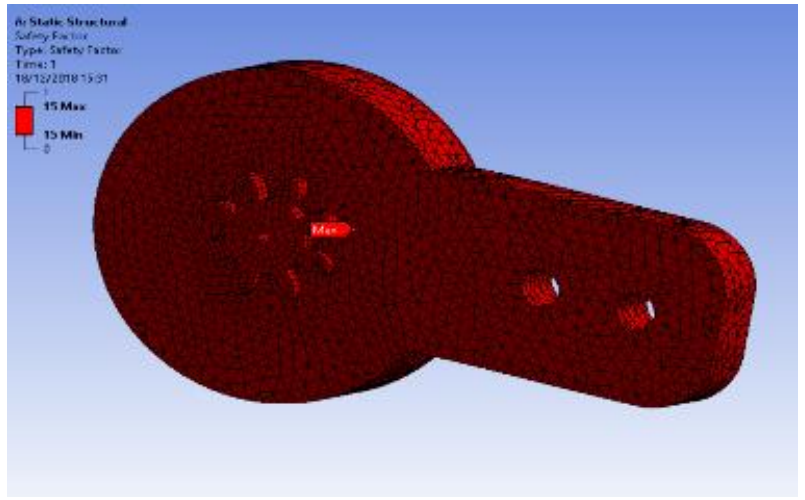

(a)

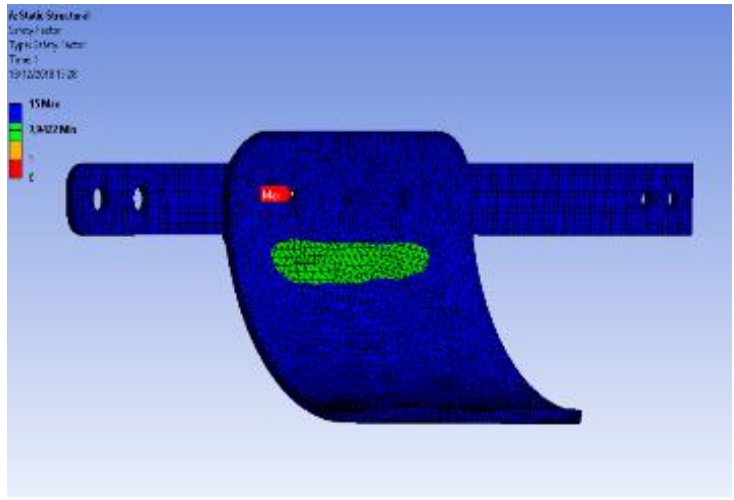

(b) 


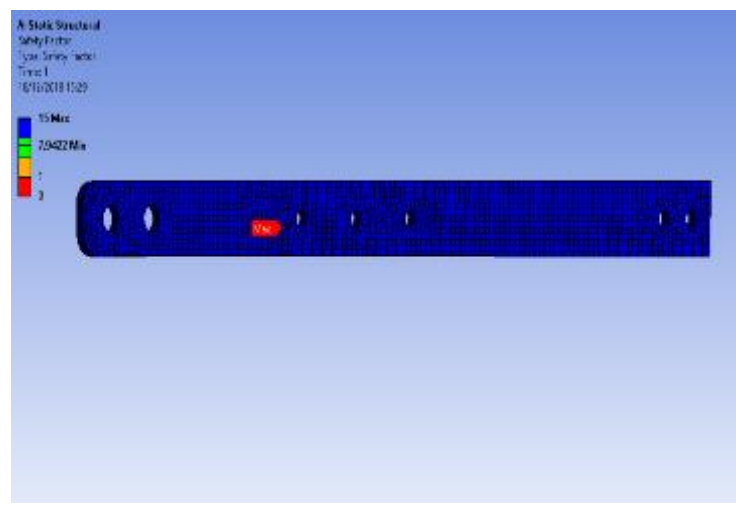

(c)

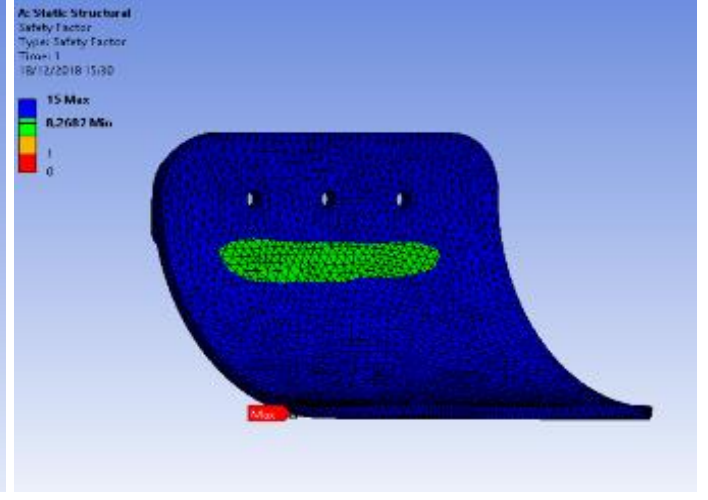

(d)

Gambar 6. Safety factor dari hasil simulasi pembebanan

Tabel 5 Hasil Simulasi part wearable elbow exoskeleton

\begin{tabular}{cccc}
\hline Bagian & Material & Safety factor & Tegangan (MPa) \\
\hline Motor - Linkage & PLA & 15 & 0,000433 \\
linkage & Allumunium & 7,94 & 25,415 \\
base & PVC & 8,26 & 3,287 \\
\hline
\end{tabular}

\section{Kesimpulan}

Hasil dari simulasi tersebut dapat dilihat tegangan maksimum dan safety factor terjadi pada 3 part cukup tinggi dimana safety factor pada ketiga part lebih besar dari 1 maka dikatakan part tersebut aman namun dengan nilai tersebut termasuk dikategorikan terlalu besar maka perlunya dilakukan optimasi pada setiap part. Untuk bagian motor-linkage tegangan maksimum sebesar $0.0016 \mathrm{MPa}$ dan safety factor sebesar 13,05. Pada linkage tegangan maksimum yang diterima sebesar 58,461 MPa dan safety factor sebesar 3,561. Sedangkan pada base tegangan maksimum yang diterima sebesar 7,624 MPa dan safety factor sebesar 3,542. Hasil kajian ini menunjukkan bahwa wearable elbow exoskeleton yang dimensinya telah ditetapkan dalam proses perancangan sebelumnya memiliki nilai analisis tegangan yang dinyatakan mampu menahan beban lengan pasien saat akan digerakkan menggunakan alat ini. Hasilnya dibuktikan dengan seluruh safety factor yang memberikan nilai lebih besar dari 1 .

\section{Daftar Pustaka}

[1] Gopura, R.A.R.C., Bandara, D.S.V., Kiguchi, K., Mann, G.K.I., 2016, 'Developments in hardware systems of active upper-limb exoskeleton robots: A review’, Robotics and Autonomous Systems 75, 203-220.

[2] Trivedi, D., Rahn, C. D., Kier, W. M. dan Walker, I. D, 2008, "Soft robotics: Biological inspiration, state of the art, and future research," Appl. Bionics Biomech., vol. 5, no. 3, pp. 99-117.

[3] Brokaw, E. B., Black, I., Holley, R. J., dan Lum, P. S., 2011 "Hand Spring Operated Movement Enhancer (HandSOME): A Portable, Passive Hand Exoskeleton for Stroke Rehabilitation," IEEE Trans. Neural Syst. Rehabil. Eng., vol. 19, no. 4, pp. 391-399.

[4] Li, J., Wang, S., Wang, J., Zheng, R., Zhang, Y., dan Chen, Z., 2012, “Development of a hand exoskeleton system for index finger rehabilitation," Chin. J. Mech. Eng., vol. 25, no. 2, pp. 223-233.

[5] Wahit M. A. A. dan Ahmad, S. A. 2017, "Design and development of low-cost exoskeleton hand robot structure," IEEE 15th Student Conference on Research and Development (SCOReD), pp. 45-49.

[6] Gearhart, C. J., Varone, B., Stella, M. H., dan Busha, B. F., 2016, "An effective 3-fingered augmenting exoskeleton for the human hand," 38th Annual International Conference of the IEEE Engineering in Medicine and Biology Society (EMBC), pp. 590-593.

[7] Richards, D. S., Georgilas, I., Dagnino, G., dan Dogramadzi, S., 2015 "Powered exoskeleton with palm degrees of freedom for hand rehabilitation," 37th Annual International Conference of the IEEE Engineering in Medicine and Biology Society (EMBC), pp. 4635-4638.

[8] Ates, S., Haarman, C. J. W. dan Stienen, A. H. A., 2017, "SCRIPT passive orthosis: design of interactive hand and wrist exoskeleton for rehabilitation at home after stroke," Auton. Robots, vol. 41, no. 3, pp. 711-723.

[9] Ismail, R., Ariyanto, M., Pambudi, K. A., Syafei, J. W., dan Ananto, G. P., 2017, "Extra robotic thumb and exoskeleton robotic fingers for patient with hand function disability," 4th International Conference on Electrical Engineering, Computer Science and Informatics (EECSI), pp. 1-6. 
[10] Annanto, G.P., Ismail, R., Haryanto, I., Ariyanto, M., Pambudi, K.A. and Pranoto, K.A., 2019, June. Numerical analysis of stress and displacement on the index finger of the prosthetic hand due to hook position. AIP Conference Proceedings, vol. 2114, No. 1, p. 050017.

[11] Ariyanto, M., Ismail, R., Setiawan, J.D. and Yuandi, E.P., 2019. Anthropomorphic transradial myoelectric hand using tendon-spring mechanism. TELKOMNIKA, 17(1), pp.537-548. 